camps too, and in public parks. Public lectures are frequent, sometimes by such leading scientists as Qian Sanquiang whom some foreigners dub the "father of atomic bombs in China".

There are popular science magazines and newspapers on sale throughout the country. No fewer than 1800 popular science books have been published since the beginning of 1978. In August 1979, an Association of Science Popularisation Writers was formed.

Science fiction based on hard science only is expected to flourish soon. Posters of great scientists are constantly in print. I saw the following: Newton, Einstein, Copernicus, Marie Curie, Darwin and the inventor Edison. But disappointingly I didn't find one of an ancient Chinese scientist. Visual arts with scientific themes are also being encouraged. More than 100 new educational films were scheduled last year.

Since May last year "universities of the air" have been started in 29 local TV and radio stations. Correspondence courses are also being extended. In a few years' time there may be twice as many students in these alternative forms of education than in the regular universities and colleges. Full-time schools are also being run to give technical instruction to administrative cadres. Party secretaries and bureau chiefs from the provincial level down and leading personnel in factories, mines and oilfields attend courses lasting two weeks to four months, in farm economics and machinery, stock-breeding, fishery, forestry, enterprise management or computers. It would be amusing for the mandarins in the British Treasury to have to go to evening classes in arithmetic.

It would be unhelpful and unrealistic to imagine that despite their enthusiasm, the Chinese have no major problems ahead. As reiterated in a recent editorial in the People's Daily, the question of manpower is the foremost obstacle to the modernisation programme, and to education in particular. Many scientists have little experience of research management: here the Chinese can learn a lot from the West provided they are selective. In the transformation of education is the teachers who constitute the single most crucial sector.

If the development of Chinese science is dependent on politics, then over the next two decades, China might well fulfil its aim of developing a science of its own. It has to be careful to avoid a Scylla of Westernisation and the Charylbdis of misguided dogmatism. The Chinese believe that the human activities grouped under the name of science are intimately related to other processes in society - "if society has a technical need, that helps science forward more than ten universities"; at the same time, dialectically the reverse is also true. Science acts on the technicoeconomic base and is therefore partially self-supporting.

\section{Friends and foes of science debate in France}

THERE is a sense of movement about French scientific policy today, a certain loosening of the tight strictures of official silence and lay apathy. What public debate there has been about science has taken place within the cloistered university circles of philosophers and sociologists, while science policy decisions continue to be taken in equal isolation by scientific and political mandarins.

Hence the strangeness to the AngloSaxon eye of the programme for a debate on science and technology policy organised by Les Amis de la Terre and held in Paris one weekend last month. There was little discussion of concrete points of technology - nuclear power safety, pollution, and so on. There was much of more epistemological questions - the nature of quantum mechanics, the question of systems analysis. But the main stress was biological; a reaction to the "biological determinism" now being vigorously propagated in France by a group of influential far-Right intellectuals (the New Right) who claim that modern biology has "proven" the inequality of races, sexes, and classes. The organisers did well in assembling, for virtually the first time in a decade, a number of top administrators, active researchers, authors and journalists to face a concerned public.

The debate started with a panel discussion among three physicistphilosophers on the interpretation of quantum mechanics. The hall was surprisingly full and the question of whether the Copenhagen interpretation was idealist or not was entered into with great gusto. But the debate was inconclusive, the question remaining rather elusive though the level of debate was one which, in the UK, would only be found in specialised seminars.

The afternoon session on bioengineering was livelier and more familiar. The panel consisted of three directors of biological research and two young researchers. The difference of opinion ran along the same line, the mandarins seeing no reason why genetic manipulation should not be prosecuted with all possible speed while the two opponents pointed out what they saw as disquieting experimental evidence and questioned the point of research. The audience of more than 100 readily joined in. They were clearly worried while the administrators were equally clearly unused to hostile questions and overracted. The scientists quoted particular experiments to support their claim that genetic manipulation was/was not dangerous but never seemed to come to grips either with each other's claims or with the general unease among the lay members of the audience.

Sociobiology, in the next session, generated a more unanimous attitude, with two of the three biologists on the panel having written recent popular books on the subject. A clear presentation of the basics of the theory, together with an uncovering of the political attitudes underlying its "objective, scientific" attack on women, non-whites, and the poor, led to one of the liveliest debates of the weekend. The discussion was continued into Saturday evening with further analysis of the particular use of women as a target by the New Right.

Sunday morning and it was the turn of systems analysis. Here both the panel and the audience were divided on the merits of a general systems approach. Some saw it as the answer, some would replace it with catastrophe theory, some saw any such search for a totalising theory which explains all levels of the universe at once as obfuscation. The search for and critique of panaceas went on into the following physics debate. Are microprocessors the solution or the problem? Will larger and larger particle accelerators advance physics as much as more modest investments elsewhere?

The final session was on social responsibility and the hall was packed to overflowing, the debate heated. The presence of trade union representatives and members of various political and environmental groups made this discussion the most familiar to the Anglo-American ear. But when one participant pointed out that "we've heard this all before, ten years ago", one was reminded of just how damaging the long silence in French public debate has been.

In any case the science policy debate has reopened in France after a long hiatus. Any facile optimism about how easy it would be to simply confront the "expert" and "the public" has evaporated after 20 hours of long and arduous discussion. For when two "experts" disagree, how is one to choose? And how can one pose the right questions without already knowing some of the answer? But Les Amis de la Terre are pleased with it and plan others for the future. 